\title{
Quando a Cirurgia Falha: Implicações da Melancolia na Cirurgia da Obesidade
}

\author{
Maria Virginia Filomena Cremasco \\ Universidade Federal do Paraná, PR, Brasil.
}

\author{
Camila Chudek Ribeiro \\ Universidade Federal do Paraná, PR, Brasil.
}

\begin{abstract}
Resumo: A obesidade tem atingido níveis epidêmicos na atualidade e constitui problema de saúde pública. Apesar de ela tradicionalmente ser tratada por meio da reeducação alimentar e da prática de atividade física, nem sempre estas medidas são eficazes para o tratamento da obesidade mórbida. Neste contexto, a cirurgia bariátrica emerge como um dos principais tratamentos que a medicina oferece atualmente para a perda de peso substancial. No entanto, estima-se que ela seja eficaz em $85 \%$ dos casos, pois há aqueles em que os pacientes acabam por recuperar parte do peso perdido e desenvolvem transtornos alimentares ou diversos comportamentos compulsivos. O presente artigo tem por objetivo compreender o sofrimento psíquico subjacente à obesidade, por meio de uma revisão bibliográfica de conceitos psicanalíticos freudianos que operacionalizam uma compreensão da dinâmica do funcionamento do aparelho psíquico, com ênfase nos conceitos de pulsão de morte, narcisismo e melancolia. A partir da análise do "Complexo da mãe morta", de André Green, sustentamos a hipótese de que algumas obesidades seriam consequência de uma tentativa de superação de uma dor melancólica, um luto que não pode ser elaborado, relacionado a uma perda narcísica.
\end{abstract}

Palavras-chave: Psicanálise, Obesidade, Cirurgia Bariátrica.

\section{When Surgery Fails: the Implications of Melancholia in the Surgical Treatment of Obesity}

\begin{abstract}
Obesity has nowadays reached epidemic levels and represents a public health issue. Despite of being traditionally treated through dietary reeducation and the practice of physical activities, these measures are not always effective to the treatment of morbid obesity. In such context, the bariatric surgery emerges as one of the main treatments for substantial weight loss that the medical science is able to currently offer. However, it is estimated that this procedure is efficient in $85 \%$ of the cases- it can be seen, for instance, cases in which the patients eventually recover part of their lost weight and therefore develop dietary disorders or several compulsive behaviors. This article aims to comprehend the psychic suffering inherent to obesity, through a bibliographic review of Freudian psychoanalytic concepts. These concepts allow the comprehension of the psychic apparatus dynamic, emphasizing the concepts of death instinct, narcissism and melancholy. Out of the analysis of the "Dead mother complex", as described by André Green, we sustain the hypothesis that some obesities might be the consequence of an attempt to overcome a melancholic pain, a mourning that cannot be worked through and that is related to a narcissistic loss.
\end{abstract}

Keywords: Psychoanalysis, Obesity, Bariatric Surgery. 


\title{
Cuando la Cirugía falla Implicaciones de la Melancolía en la Cirugía de la Obesidad
}

\begin{abstract}
Resumen: La obesidad ha alcanzado niveles epidémicos en la actualidad y constituye un problema de salud pública. A pesar de ser tradicionalmente tratada por medio de reeducación alimentaria y práctica de actividad física, no siempre esas medidas son eficaces para el tratamiento de la obesidad mórbida. En este contexto, la cirugía bariátrica emerge como uno de los principales tratamientos para la pérdida de peso sustancial que la medicina ofrece actualmente. Sin embargo, se estima que ella sea eficaz en el $85 \%$ de los casos - observamos, por ejemplo, casos en los cuales los pacientes acaban por recuperar parte del peso perdido y desarrollan trastornos alimentarios o diversos comportamientos compulsivos. El presente artículo tiene por objetivo comprender el sufrimiento psíquico subyacente a la obesidad, por medio de una revisión bibliográfica de conceptos psicoanalíticos freudianos que tornan operativa una comprensión de la dinámica del funcionamiento del aparato psíquico, con énfasis en los conceptos de pulsión de muerte, narcisismo y melancolía. A partir del análisis del "Complejo de la madre muerta", de André Green, sustentamos la hipótesis de que algunas obesidades serían consecuencia de un intento de superación de un dolor melancólico, un luto que no puede ser elaborado, relacionado con una pérdida narcisista.
\end{abstract}

Palabras clave: Psicoanálisis, Obesidad, Cirugía Bariátrica.

A obesidade tem atingido níveis epidêmicos na atualidade. De acordo com a Organização Mundial da Saúde (OMS), em 2005 o mundo teria 1,6 bilhão de pessoas acima de 15 anos de idade com excesso de peso (IMC $\geq 25 \mathrm{~kg} / \mathrm{m}^{2}$ ) e 400 milhões de obesos $\left(\mathrm{IMC} \geq 30 \mathrm{~kg} / \mathrm{m}^{2}\right)$. Estima-se que, em 2015, estes números cheguem a 2,3 bilhões de pessoas com excesso de peso e 700 milhões de obesos, o que representaria $75 \%$ de aumento nos índices de obesidade em apenas dez anos (Melo, 2011).

A obesidade é considerada uma doença crônica e grave, definida como um acúmulo excessivo de gordura corpórea numa magnitude tal que traga prejuízos à saúde (Coutinho, 1999) e deriva-se de múltiplos fatores, dentre eles: comportamento alimentar, genética, mecanismos de armazenamento de gordura, regulação do aporte e gasto energético, fatores ambientais, como os hábitos alimentares e a condição de renda de cada comunidade, e ainda, fatores psicológicos (Loli, 2000). Além de todas as complicações físicas, com altas taxas de morbidade e mortalidade, deparamo-nos, muitas vezes, com um grande sofrimento associado à obesidade.

Este caráter multifatorial torna seu tratamento mais complexo e, apesar de tradicionalmente ser tratada de maneira clínica, por meio de reeducação alimentar e prática de exercícios físicos, nem sempre estas medidas são eficazes para o tratamento da obesidade mórbida (caracterizada por IMC $\geq 40$ ). A cirurgia bariátrica surge, então, como o principal tratamento cirúrgico que a medicina oferece atualmente para a perda de peso substancial e duradoura.

De acordo com Oliveira, Linardi e Azevedo (2004), as cirurgias bariátricas ou antiobesidade podem ser divididas didaticamente em três categorias: os procedimentos restritivos, que diminuem a capacidade do estômago; os mal-absortivos, que modificam a digestão; ou ainda uma combinação de ambas as técnicas. Os critérios de indicação para a cirurgia são:

IMC maior que $40 \mathrm{~kg} / \mathrm{m}^{2}$ ou IMC acima de $35 \mathrm{~kg} / \mathrm{m}^{2}$, associado com doenças com, no mínimo, cinco anos de evolução e que melhorem com a perda de peso, como diabetes melito e hipertensão arterial, doenças osteoarticulares (principalmente de membros inferiores), apnéia do sono, histórico de falha de tratamentos conservadores prévios e ausência de doenças endócrinas como causa da obesidade (Oliveira et al., 2004, p. 200).

Tais cirurgias possuem um alto índice de sucesso (estima-se que elas sejam eficazes em cerca de $85 \%$ 
dos casos), porém, é comum encontrarmos, tanto na clínica quanto na literatura especializada, casos nos quais os pacientes recuperam grande parte do peso perdido, desenvolvem transtornos alimentares como a anorexia - caracterizada por "perda de peso intensa e intencional às expensas de dietas extremamente rígidas com uma busca desenfreada pela magreza, uma distorção grosseira da imagem corporal e alterações do ciclo menstrual" (Cordás, 2004, p. 155) -, a bulimia caracterizada por episódios nos quais ocorrem "grande ingestão de alimentos com sensação de perda de controle [...] preocupação excessiva com o peso e a imagem corporal que levam o paciente a métodos compensatórios inadequados para o controle de peso como vômitos auto-induzidos, uso de medicamentos (diuréticos, inibidores de apetite, laxantes), dietas e exercícios físicos" (Cordás, 2004, p. 155) - e o transtorno da compulsão alimentar periódica (TCAP) - caracterizado por ataques de "compulsão alimentar com subseqüente angústia devido à ausência de comportamentos regulares voltados para eliminação do excesso alimentar" (Stefano, Borges, \& Claudino, 2002, s.p.) -, ou ainda adotam diversos comportamentos como o comprar compulsivo e o abuso de álcool e outras substâncias.

Gurfinkel (2011) apresenta uma pesquisa realizada pela Unifesp que observa que $20 \%$ dos ex-obesos submetidos à cirurgia de redução de estômago apresentam posteriormente algum tipo de comportamento compulsivo, como o alcoolismo, o abuso de cigarro e outras drogas, de jogos ou de sexo. Cordás, Lopes Filho e Segal (2004) realizaram um levantamento sobre casos de evolução pós-cirúrgica para anorexia nervosa e bulimia nervosa, apresentando um estudo de caso no qual a paciente apresentou alterações comportamentais alimentares compatíveis com a sintomatologia da anorexia e apontando situações semelhantes na literatura nas quais se evidenciam alterações comportamentais relativas à alimentação, incluindo um estudo que descreve um caso que apresentou, além da problemática alimentar, também abuso de drogas (Scioscia et al.,1991, apud Cordás, Lopes Filho e Segal, 2004). Outro estudo (Waters, Pories, Swanson, Meelheim, Flickinger, \& May, 1991) realizado com 157 pacientes ao longo de três anos pós-cirurgia registrou três suicídios e duas mortes relacionadas ao abuso de álcool, destacando a importância do acompanhamento da saúde mental em longo prazo nesta população.

Estes resultados nos alertam para a necessidade de superar a compreensão da tradicional obesidade apenas como uma doença que deve ser combatida a qualquer custo, buscando compreendê-la como uma expressão de um sofrimento psíquico que acaba por se associar a psicopatologias e comorbidades que não só não se resolvem com a cirurgia, quanto podem, a partir dela, se manifestarem. Não pretendemos negar as diversas facetas que a constituem, porém, neste trabalho, buscamos compreender o sofrimento psíquico subjacente à obesidade. Para tanto, apoiamo-nos na psicanálise, a partir de seus conceitos fundamentais que operacionalizam a compreensão do funcionamento do aparelho psíquico.

Freud propõe, com a psicanálise, um método de investigação do inconsciente, dando à subjetividade um lugar privilegiado na compreensão dos padecimentos que acometem o indivíduo, distinguindo-a da Psicopatologia Geral, que se ocupa, sobretudo, da observação e da descrição sintomáticas, como podemos observar em manuais como o Manual de Diagnóstico e Estatística da Associação Psiquiátrica Americana - DSM-V (American Psychiatric Association, 2014) e A Classificação Internacional de Doenças - CID-10 (Organização Mundial da Saúde, 1993). O objetivo principal da Psicopatologia Geral é propiciar uma linguagem padronizada entre pesquisadores e clínicos de diferentes abordagens teóricas. Trata-se, como destaca Ceccarelli (2005), de um sistema de classificação que tem como uma das principais críticas justamente certa negligência com a questão da subjetividade, tanto daquele que está sendo "classificado" quanto daquele que classifica.

Como uma alternativa ao empobrecimento da interpretação e da compreensão qualitativa em psicopatologia, foi criada na década de 1970 a Psicopatologia Fundamental, introduzida por Pierre Fédida na Universidade Paris VII - Denis Diderot. Ela não se limita à mera descrição e criação de sistemas classificatórios, mas sim se posiciona visando recuperar um discurso sobre o pathos psíquico (Berlinck, 2010). Portanto, a Psicopatologia Fundamental, que aqui assumimos como nossa perspectiva de análise e que tem a psicanálise como epicentro, não pretende negar as contribuições advindas da Psicopatologia Geral, e sim propor a possibilidade de um diálogo intercientífico entre diferentes perspectivas teóricas que se interessam pelo sofrimento psíquico, estabelecendo "uma reflexão crítica dos modelos existentes e uma discussão dos paradigmas que afetam nossos objetos de pesquisa, nossas teorias e nossas práticas" (Ceccarelli, 2005, p. 7). 
A Psicopatologia Fundamental é uma linguagem (logos) sobre o sofrimento (pathos) psíquico levando em consideração a subjetividade. Ela é Fundamental por dois motivos: 1. distingue-se da Psicopatologia Geral proposta por Karl Jaspers e 2. baseia-se no Princípio do Fundamento (nihil est sine ratione). O Livro de Berlinck (2000) intitulado Psicopatologia Fundamentalse aprofunda na descrição de tal campo de pesquisa.

A Psicopatologia Fundamental adota o método clínico como o procedimento lógico mais adequado para a compreensão do sofrimento humano (Associação Univeristária de Pesquisa em Psicologia Fundamental, 2016).

Berlinck (1997) destaca que a descoberta do inconsciente freudiano como manifestação do pathos e a consequente metapsicologia da psicanálise a tornam a principal casa para a Psicopatologia Fundamental. A psicanálise, a partir da dimensão do desejo, faz uma ruptura epistemológica frente a esta Psicopatologia Geral: "Freud postula que o sujeito - louco ou não sempre que fala, fala do, e a partir de, seu pathos, que aqui se confunde com a trama discursiva que o constitui" (Cecarelli, 2005, p. 5). O autor define o pathos como um "excesso de paixões" (ou de desejo) que se torna patológico, trazendo sofrimento e levando ao assujeitamento, à perda de si. Podemos observar na obesidade, foco de nosso trabalho, a presença do excesso que assujeita, representada tanto no sobrepeso inerente ao obeso, quanto na sua vontade desmedida do comer, muito além das suas necessidades nutricionais.

$\mathrm{O}$ autor destaca que estamos vivendo um momento no qual "observa-se um movimento cada vez maior no sentido de eliminar a dor - de evitar contato consigo mesmo - do que para transformá-la em experiência" (Cecarelli, 2005, p. 11). Para o autor, a essência de Psicopatologia consiste no conhecimento da paixão e do sofrimento psíquico, na qual o pathos, em si, nada ensina; no entanto, quando se trata de uma experiência terapêutica e metapsicológica, adentra-se no campo da Psicopatologia Fundamental, com a possibilidade de transformação do pathos em experiência, o que significa considerá-lo não apenas como um estado transitório mas, e talvez sobretudo, como algo que alarga ou enriquece o pensamento. Sob este enfoque, não abordaremos a obesidade como um problema por si, colocando em segundo plano discussões nosográficas, por exemplo, envolvendo os índices de massa corporal; o foco está, portanto, na reflexão acerca do sofrimento psíquico subjacente a ela, e não apenas nos comportamentos do indivíduo que dela padece.

\section{A Psicodinâmica da obesidade a partir da psicanálise}

Iniciaremos com uma breve revisão de alguns conceitos freudianos fundamentais que nos auxiliam na apreensão da psicodinâmica da obesidade, para que sirvam de guia de compreensão a leitores de diversas áreas que atuam com problemas alimentares e que, indubitavelmente, deparam-se com o sofrimento psíquico de seus clientes.

Um dos conceitos centrais na obra de Freud (1905/1996) é o conceito de pulsão, entendido como algo que se situa na fronteira entre o mental e o somático, como uma carga energética produzida no corpo em direção à psique; portanto, algo que tem origem numa fonte somática na qual desperta uma excitação (libido) e que faz uma exigência de trabalho ao aparelho psíquico, ou seja, uma associação a uma representação. Roudinesco (1997) define a pulsão como a carga energética que está na origem da atividade motora e do funcionamento psíquico inconsciente do homem. Seria como uma necessidade que se associaria a uma representação ideativa - a necessidade ou desejo de comer (pulsão de comer ou nutrição, por exemplo). Comer em desmedida marcaria, então, uma desregulação, por assim dizer, da economia pulsional e, consequentemente, libidinal, como veremos a seguir. Mas, é exatamente onde o querer pulsional não atende à necessidade fisiológica, que desvia de suas fontes $\mathrm{e}$ de seus objetos específicos, que fica desvelado o caráter disruptivo da pulsão, ou seja, ela atesta o querer no humano que não se esgota em suas ações, nunca se satisfaz completamente. Portanto, isso que se situa entre o somático e o psíquico não se esgota (satisfaz) simplesmente em uma descarga mantendo internamente um quantum de energia (excitação sexual) sempre impulsionando à satisfação libidinal.

Libido é uma força quantitativamente variável que se relaciona com os processos e transformações ocorrentes no âmbito da excitação sexual, ou seja, a carga energética contida na pulsão (Freud, 1905/1996). Importante ressaltar que esta excitação não é fornecida apenas pelas partes sexuais, mas sim por todos os órgãos no corpo. Deste modo, o desejo manifesto na fome voraz do obeso não está necessa- 
riamente associado a uma pressão originária do aparelho digestivo do sujeito, podendo advir de várias outras partes de seu corpo. Assim, o que é frequentemente entendido como fome para o compulsivo alimentar, pode ser uma pulsão erroneamente interpretada. É o que vemos nos relatos de pacientes para os quais comer é a resposta a todas as suas necessidades, indiscriminadamente.

É necessário que haja uma organização psíquica para lidar com essas tensões produzidas somaticamente. Freud (1894/1996) defende que o aparelho psíquico opera de acordo com o "princípio de constância", ou seja, uma tendência a manter a quantidade de excitação do organismo tão baixa quanto possível. Em 1900, Freud levanta a hipótese de que este aparelho psíquico operaria segundo o esquema de um arco reflexo, utilizando a motilidade como via de descarga, chegando a uma "vivência de satisfação" que poria fim ao estímulo interno. $O$ autor levanta também uma segunda hipótese, na qual o acúmulo de excitação seria vivido como desprazer, colocando o aparelho em ação com vistas a repetir a vivência de satisfação, sentida como prazer (Freud, 1900/1996). Esta corrente que parte do desprazer e aponta para o prazer é chamada de desejo, e seria este desejo o que colocaria o aparelho psíquico em movimento. Nesta perspectiva, "o curso da excitação dentro dele é automaticamente regulado pelas sensações de prazer e desprazer" (Freud, 1900/1996, p. 625). Este princípio é inicialmente denominado como "princípio do desprazer" que, posteriormente, será conhecido como "princípio do prazer", no qual a atividade do aparelho mental seria regulada por sensações de prazer-desprazer, buscando uma redução na tensão por intermédio da obtenção de prazer, evitando o desprazer.

Ainda neste momento de sua obra, o autor se utiliza de dois processos para explicar o que rege o funcionamento do aparelho psíquico: o processo primário e o processo secundário. De acordo com Freud, "a atividade do primeiro sistema está orientada para garantir a livre descarga [...], enquanto o segundo sistema, por meio das catexias que dele emanam, consegue inibir esta descarga e transformar a catexia numa catexia quiescente" (Freud, 1900/1996, p. 625-626), ou seja, ligada e contida dentro de uma rede de representações. A observação destes processos nos fornece o protótipo e primeiro exemplo do recalcamento psíquico, que seria "essa evitação de lembrança de qualquer coisa que um dia foi aflitiva, feita sem esforço e com regularidade pelo processo psíquico" (Freud, 1900/1996, p. 626). Nestes termos, o primeiro sistema seria incapaz de introduzir qualquer coisa desagradável no contexto de seus pensamentos. Já o segundo sistema buscaria encontrar um método de catexizar as lembranças desprazerosas, visando a liberação deste desprazer, destacando que "o segundo sistema só pode catexizar uma representação se estiver em condições de inibir o desenvolvimento do desprazer que provenha dela" (Freud, 1900/1996, p. 627).

Deste modo, podemos pensar no comer do obeso como uma tentativa de diminuir o nível de tensão do aparelho psíquico, nos moldes do princípio de constância. Vista sob a ótica do princípio do prazer, a atividade de comer compulsivamente evitaria o desprazer e buscaria, ainda, a obtenção de prazer. Nestes termos, o comer poderia ser considerado uma forma de erotismo, uma satisfação sexual substitutiva, no qual o prazer seria alcançado pela via oral. Cabe destacar que a libido comporta diversas possibilidades para sua satisfação, por uma via corpórea qualquer; o que observamos em algumas patologias, no entanto, é a priorização de uma via específica, uma fixação de zona. No caso da obesidade, como já vimos, esta satisfação seria obtida oralmente, substituindo sintomaticamente outras formas de satisfação.

Freud (1917a/1996) afirma que o objetivo dos sintomas é a satisfação sexual ou uma defesa contra ela, no caso de ser ameaçadora ao equilíbrio psíquico, sendo que na histeria predominaria o caráter positivo da realização de um desejo inconsciente, enquanto na neurose obsessiva predominaria o caráter negativo, ascético. Compreendemos, então, que o sintoma é uma formação de compromisso, que possibilita que conteúdos recalcados e mantidos inconscientes sejam elaborados de maneira a serem admitidos no consciente.

O recalque é, portanto, um esforço psíquico para afastar determinadas representações (pensamentos, imagens, recordações) da consciência, quando representam uma ameaça ao aparelho psíquico, e é operacionalizado pelo superego ${ }^{1}$. Freud $(1905 / 1996)$ irá denominar como "saída para a doença" o movimento que não soluciona este conflito entre a necessidade

${ }^{1}$ Instância postulada por Freud (1923), cujo papel é próximo ao de um juiz e censor em relação ao ego; é a instância portadora do ideal de eu e herdeiro do Complexo de Édipo. Freud (1923/1996). 
de satisfação da pulsão e as resistências do sujeito, mas procura escapar dele pela transformação desta libido recalcada em sintomas. Portanto, para o autor, os sintomas consistiriam em um tipo de satisfação sexual substitutiva, podendo ser patológicos ou não. No entanto, o que está por trás deste sintoma é sempre um desejo, e o sintoma corresponderia ao retorno do material reprimido, ou seja, a uma falha do processo de repressão. Neste sentido, para a psicanálise, o sintoma seria o "substituto" da doença, uma metaforização do sofrimento do sujeito; diante de um conflito no centro do eu, entre uma representação sobrecarregada que visa liberar seu excedente de energia e a pressão constante do recalcamento que, por meio do isolamento desta representação, a impossibilita de escoar sua sobrecarga. O sintoma surgiria como uma solução de compromisso, da mesma forma que se apresentam as outras produções do inconsciente como os sonhos, os atos falhos e os chistes: uma representação de compromisso entre o que estaria recalcado e a energia associada a isto que deveria ser descarregada.

Um dos mecanismos de formação de sintomas é a conversão, que opera na histeria e que consiste em "uma transposição de um conflito psíquico e numa tentativa de resolvê-lo em termos de sintomas somáticos" (Laplanche, \& Pontalis, 2001, p. 103). Os autores destacam que o sintoma conversivo traz como especificidade uma significação simbólica, consistindo em uma expressão, pelo corpo, de uma representação recalcada. Esta significação simbólica nos remete ao funcionamento do processo secundário visto anteriormente, que possibilita uma descarga pulsional modulada e, portanto, mais lenta e parcial.

Tais conceitos são fundamentais para a compreensão da obesidade como um sintoma. O comer pode ser observado a partir do princípio de constância e do princípio do prazer, reduzindo a tensão do aparelho psíquico (e evitando o desprazer) por intermédio da obtenção de prazer. Sob este enfoque, o comer compulsivo do obeso pode ser compreendido como um sintoma, uma satisfação sexual substitutiva gerada por uma falha na repressão, e a dificuldade do obeso em livrar-se deste sintoma residiria justamente no prazer envolvido neste ato - um prazer não apenas nutricional (autoconservador), mas também libidinal (sexual).

No entanto, observamos que em alguns pacientes o comer excessivo parece prestar-se mais a uma necessidade psíquica do que à obtenção de prazer; ainda que tenham consciência dos prejuízos em termos de sua saúde física e que possuam vasto conhecimento de diversas dietas, valores calóricos, dentre outros, algo "escapa" a estes sujeitos, que parecem ficar sem controle diante da voracidade de seu comer que, por vezes, nem ao menos lhes proporciona prazer. Encontramos ainda sujeitos que relatam emagrecimento e posterior dificuldade em manter-se no peso desejado ou que, diante de algum sucesso nos tratamentos empreendidos, acabam por abandoná-los. Para compreender estes casos que convocam o que iremos por hora nomear como uma dimensão mortífera, apoiamo-nos na segunda teoria das pulsões postulada por Freud a partir de 1920.

Em "Além do princípio do prazer", Freud (1920/1996) atualiza sua teoria das pulsões. Até este momento de sua obra (Freud, 1915/1996), Freud dividia as pulsões em dois grupos: as pulsões sexuais e as pulsões de autopreservação ou do ego. O sadismo e o ódio estariam relacionados com as pulsões do ego. Com a introdução do conceito de narcisismo, a distinção entre as pulsões sexuais e de autopreservação é apagada, pois ambas são colocadas como modalidades da libido. Neste contexto, Freud parece encontrar dificuldades para localizar o ódio sem deduzir um monismo pulsional (Laplanche, \& Pontalis, 2001). O conceito de ambivalência e a crescente importância do ódio e da agressividade para a clínica psicanalítica, manifestando-se, por exemplo, no fenômeno da reação terapêutica negativa - uma forte resistência à cura, relacionado com sentimento de culpa inconsciente - mobilizam Freud à elaboração de um novo dualismo pulsional. Além disso, a observação de certos fenômenos de repetição - processos inconscientes nos quais o sujeito se coloca ativamente em situações penosas - apontaram para a existência de forças independentes e até mesmo capazes de se oporem ao princípio do prazer, marcando o caráter regressivo das pulsões.

Freud passa a englobar as pulsões sexuais e de autopreservação no que será chamado então de pulsões de vida - que tendem a constituir e manter ligações, preservando a existência do sujeito (Laplanche, \& Pontalis, 2001) - e insere o conceito de pulsões de morte, pulsões estas que não seriam representáveis, como uma tendência presente em todos os seres vivos em direção à destrutividade, à descarga total e imediata das excitações e, consequentemente, associada a vivências de total plenitude e satisfação, vivências associadas a "um estado para sempre 
perdido - o estado nirvânico -, em que não haveria dor nem representação" (Berlinck, 2000, p. 28). A pulsão de morte é, então, uma pulsão por excelência, uma pulsionalidade pura que realiza de forma eminente o caráter regressivo das pulsões; em síntese, enquanto as pulsões de vida - sexuais e de autoconservação - buscam instituir ligações cada vez maiores, ligando a energia livre do aparelho psíquico, a meta da pulsão de morte é a destruição destas ligações (Freud, 1938/1996).

Minerbo (2009, p. 129) destaca o caráter imediatista da pulsão de morte ao afirmar que seu objetivo é "a descarga da excitação para fora do aparelho psíquico pelo caminho mais rápido. Se isso não ocorre, é porque o ego se encarrega de modular a violência do ataque pulsional e de fazer as necessárias ligações". Porém, se não há uma rede de representações suficientemente capaz de conter a pulsão dentro do aparelho psíquico ou se a pulsão é irrepresentável, esta pulsionalidade não ligada, mortífera, pode ser descarregada para fora do aparelho psíquico sob a forma de um ato no corpo, uma ação impulsiva que rompe com o comportamento habitual do sujeito (Laplanche, \& Pontalis, 2001). Dentro desta perspectiva entendemos, então, que algumas manifestações da obesidade podem ser consequências de uma tentativa de expressar por meio de um ato (o comer excessivo) uma pulsão irrepresentável. De acordo com Loli (2000), haveria nestes pacientes uma incapacidade de lidar com seus conflitos psíquicos internamente, sendo a obesidade, nestes casos, uma expressão por meio do corpo de algo que não pode ser expresso pela via da fantasia, do pensamento ou mesmo da linguagem.

Neste sentido, o obeso utiliza a sua alimentação como uma defesa diante da angústia, engolindo frustrações, relações e objetos. Fédida (1978) evoca a figura do canibal para nos colocar em contato com esta pulsionalidade devastadora primitiva que, ao mesmo tempo devora o objeto, destruindo-o, realiza sua incorporação ao torná-lo parte de si. O autor esclarece que esse ato busca superar a perda do objeto, expressa pelo desejo de incorporá-lo, destruindo-o. Simultaneamente afirma e nega a separação entre o eu e o objeto. O autor destaca a relação entre este mecanismo de identificação primitiva e a melancolia:
L'identification narcissique primitive et telle que l'angoisse de la perte de l'objet d'amour se laisse interpreter comme l'angoisse du moi de ne pouvoir se survivre au-delà de la disparition de l'objet: la mélancolie est moins la réaction régressive à la perte de l'objet que la capacite fastasmatique (ou hallucinatoire) de le maintenir vivant comme objet perdu (Fédida, 1978, p. 65-66) ${ }^{2}$.

A ideia do canibalismo evoca, então, uma unidade violenta, de todo limite perdido, de um desejo de se apropriar do objeto destruindo-o, devorando-o. Comer demais como forma incorporadora do objeto para tamponar, ou mesmo negar, o medo de perdê-lo: delineamos assim nossa compreensão sobre algumas obesidades se associarem a um sofrimento melancólico.

No clássico texto "Luto e melancolia" (1917b/1996), Freud define a melancolia como uma neurose narcisista, na qual há o direcionamento da libido para o próprio eu. A melancolia pode ser definida como um estado no qual há

um desânimo profundamente penoso, a cessação de interesse pelo mundo externo, a perda da capacidade de amar, a inibição de toda e qualquer atividade e uma diminuição dos sentimentos de autoestima a ponto de encontrar expressão em auto-recriminação e autoenvilecimento, culminando numa expectativa delirante de punição (Freud, 1917b/1996, p. 250).

Antes de passarmos para uma análise das especificidades deste padecimento, faz-se necessária uma breve introdução ao tema do narcisismo, fundamental para o entendimento do sofrimento que aqui abordamos.

\section{Breves considerações acerca do narcisismo}

Freud (1914/1996) descreve o narcisismo como a maneira de uma pessoa tratar seu próprio corpo da mesma forma pela qual o corpo de um objeto sexual é comumente tratado, obtendo satisfação disso. Importante ressaltar que o narcisismo é um complemento libidinal egoico ao instinto de preservação, e parte do

\footnotetext{
2 "A identificação narcisista primitiva é aquela na qual a angústia da perda do objeto de amor é vivida como uma angústia do eu de não ser capaz de sobreviver para além do desaparecimento do objeto; a melancolia é menos a reação à perda do objeto que a capacidade fantasística (ou alucinatória) de mantê-lo vivo como objeto perdido (Fédida, 1978, p. 65-66, tradução nossa).
} 
desenvolvimento normal dos indivíduos, visto que certa quantidade de libido é necessária para a proteção do indivíduo. Nas neuroses narcisistas, como a melancolia, no entanto, estas defesas atingiram um patamar tão excessivo que se tornaram, elas próprias, fonte de sofrimento.

As neuroses narcisistas, dentre elas a melancolia, se relacionam diretamente com a constituição da instância denominada "ideal do eu". Segundo Freud (1914/1996), o ego infantil se veria, durante a primeira infância, como sendo possuído de toda perfeição de valor; assim, o ego real e ego ideal seriam, neste caso, a mesma coisa. Quando adulto, o homem se vê perturbado pelas admoestações de terceiros e por seu próprio julgamento crítico e perde a sua "perfeição", sua onipotência narcísica, buscando recuperá-la sob a nova forma de um ideal de ego. O que ele então projeta diante de si como sendo seu ideal é o substituto do narcisismo perdido de sua infância (ego ideal). Este ideal do ego servirá como matriz para os processos de repressão do sujeito - formando o que Freud posteriormente chamará de superego - e atuará como um agente de censura. Na melancolia, há uma hiperatividade patológica deste agente, evidenciado nas constantes críticas e admoestações que o melancólico impõe a si mesmo.

Este ideal do ego se colocará para o sujeito como um projeto identificatório, algo que o sujeito deve atingir para constituir seu amor-próprio. Minerbo (2009) destaca que o ideal de ego neurótico foi capaz de elaborar o luto pela sua onipotência narcísica perdida. No entanto, diante de uma falha na inscrição primária do narcisismo, este luto não pode ser elaborado, como veremos na citação a seguir:

Uma mãe que não 'narcisou' suficientemente seu bebê (por exemplo, fazendo-o crer que havia algo de errado com ele) não sustentou o ego ideal pelo tempo necessário. Assim, a busca de ser o próprio ideal - a busca pela perfeição narcísica, condição para ser amado pelas figuras parentais - continua pela vida afora (Minerbo, 2009, p. 146).

A autora destaca neste trecho a importância da relação entre mãe/bebê para a inscrição deste narcisismo primário e, consequentemente, do ego ideal, já que é neste momento que se inscreve no bebê uma imagem jubilosa de si. Ao abordarem a questão do olhar materno na subjetivação do bebê, Pinheiro,
Quintella e Verztman (2010) ressaltam que, quando o olhar materno não circunscreve este sujeito, não o insere na dinâmica da pluralidade identificatória, resta ao bebê apenas uma profunda identificação com o nada, que o lança em um vazio sem precedentes. Tal vazio é queixa constante na clínica de pacientes obesos que tentam, por intermédio da comida, não somente tamponar o vazio corporal mas afastar-se da angústia do vazio, normalmente expressa em sensações corporais não descritíveis ou representáveis, que os levam compulsivamente a comer.

Green (1988) desenvolve estudos acerca do narcisismo e lança bases para a compreensão das marcas psíquicas deixadas na criança pela sua relação primeira com a mãe, momento determinante para o destino de seus investimentos libidinais, objetais e narcisistas. $\mathrm{O}$ autor associa as perturbações na relação mãe-criança e as consequências psíquicas da perda do seio, por exemplo, ao que ele denomina "clínica do vazio" ou clínica do negativo - a negatividade enquanto aquilo que não pode ser representado, nomeável. Para ele, a angústia da perda do seio traduz uma perda sofrida ao nível do narcisismo, e é resultado de um desinvestimento massivo, radical e temporário de um objeto primário, que imprime marcas no inconsciente sob a forma de buracos psíquicos. As contribuições trazidas a partir da análise do chamado 'complexo da mãe morta', que veremos a seguir, ampliam nossa compreensão sobre uma perda que não pode ser elaborada, um dos traumas que se encontram no cerne do posicionamento melancólico.

\section{A mãe morta e a melancolia}

Como vimos anteriormente, a melancolia, assim como o luto, constitui reação à perda de um objeto amado, no entanto, trata-se de uma perda de natureza mais ideal, ou seja, o objeto não precisa ter deixado de existir, mas ter sido perdido enquanto objeto de amor. Assim, o melancólico pode não ver, claramente, o que foi perdido - sabe quem ele perdeu, mas não o que perdeu nesse alguém. $\mathrm{O}$ autor destaca, desde o início, que na melancolia trata-se de uma perda na vida $p u l$ sional (Freud, 1895/1996).

Cabe aqui retomarmos as contribuições de Green (1988), ressaltando que, no complexo da mãe morta, não estamos tratando da morte real desta mãe. Em consequência de uma depressão materna, ela passa de um objeto vivo, fonte de vitalidade, para uma figura distante; a mãe morta, então, "perma- 
nece viva, mas que está, por assim dizer, morta psiquicamente aos olhos da pequena criança de quem ela cuida" (Green, 1988, p. 239). O autor postula uma depressão infantil que se dá na presença de um objeto - a mãe - ele mesmo absorto em um luto, seja ele reação à perda de um ente querido ou uma depressão decorrente de uma ferida narcisista, que acarreta em uma diminuição do interesse e um grande desinvestimento materno pela criança.

Este desinvestimento é vivenciado pela criança como uma catástrofe e como um trauma narcísico, e irá demarcar para ela não apenas a perda do amor, como também a de sentido, visto que lhe faltam recursos psíquicos para elaborar o que lhe ocorreu. O complexo da mãe morta irá engendrar no psiquismo da criança um grande esforço no sentido de evitar o desaparecimento deste objeto primário, constituindo um luto inelaborável ou luto branco (Green, 1988) - branco este que remete aos buracos deixados pelas perdas narcísicas, em oposição ao vermelho sangrento a que remetem as angústias relativas à castração que são angústias identificáveis: medo da perda do pênis, perda de poder, perda corporal etc.

O luto inelaborável, isto é, que não aceita a perda e se fixa no objeto, suscita uma série de defesas diante desta angústia, sendo a primeira e mais importante delas um desinvestimento do objeto materno mas uma identificação inconsciente com a mãe morta. Green (1988, p. 249) destaca que este desinvestimento resulta na "constituição de um buraco na trama das relações objetais com a mãe". Juntamente a este desinvestimento, ocorre uma identificação segundo um modelo bastante primitivo, incorporador, cuja finalidade é não apenas manter o objeto, mas possuí-lo de forma a tornar-se o objeto, conservando-o de modo canibalístico. $\mathrm{O}$ autor enfatiza que ocorre uma transformação da identificação positiva em identificação negativa diante da mãe morta, ou seja, a identificação do sujeito não com o objeto materno, mas com o buraco deixado em decorrência de seu desinvestimento. Fica assim o sujeito diante de um seio ausente e não um seio que fora perdido; que não pode ser preenchido e nem é preenchedor.

Green (1988) destaca que o complexo da mãe morta pode estar presente em qualquer neurose, no entanto, podemos perceber semelhanças com o padecimento melancólico. Se a melancolia consiste em uma reação diante da perda de um objeto e utiliza como mecanismo uma identificação com este objeto, somos levados a questionar as implicações de uma identificação negativa com o objeto primário ausente, que acarretam uma identificação com o nada e uma decorrente sensação de vazio.

A melancolia absorve o ego em um processo semelhante ao do luto, exigindo a retirada das ligações libidinais com o objeto perdido, processo este que absorve o eu e é responsável pela inibição melancólica e pelo desinteresse no mundo externo observados nesta afecção. No entanto, a melancolia emerge justamente da impossibilidade de elaborar este luto que se trata de uma perda narcísica. Na obesidade, podemos pensar esta tentativa de isolamento do mundo externo inclusive na gordura corporal do sujeito obeso, que o protege e o isola do contato com os outros. Haveria, então, nestes sujeitos, um tipo de fechamento contra do mundo, ou seja, uma existência melancólica que volta sua atenção para o próprio ego em uma tentativa de defesa diante da angústia da perda do objeto.

O melancólico exibe também uma diminuição de sua autoestima, um empobrecimento egoico que se observa pelas constantes críticas e repreensões que o melancólico impõe a si. Observamos que, no melancólico, "uma parte de seu ego se coloca contra a outra, julga-a criticamente e, por assim dizer, toma-a como seu objeto" (Freud, 1917b/1996, p. 253). Esta diminuição da autoestima na melancolia aponta para um empobrecimento do ego do sujeito melancólico, indicando uma perda egoica, no entanto, a analogia com o luto estabelecida por Freud nos leva a entender a melancolia como uma perda referente a um objeto. Freud explica esta contradição ao considerar que:

Se se ouvir pacientemente as muitas e variadas auto-acusações de um melancólico, não se poderá evitar, no fim, a impressão de que freqüentemente as mais violentas delas dificilmente se aplicam ao próprio paciente, mas que com ligeiras modificações, se ajustam realmente a outrem, a alguém que o paciente ama, amou ou deveria amar [...] as auto-recriminações são recriminações feitas a um objeto amado, que foram deslocadas desse objeto para o ego do próprio paciente (Freud, 1917b/1996, p. 254).

Há, portanto, uma identificação do ego com o objeto abandonado: a sombra do objeto cai sobre o ego que passa, então, a ser julgado por um agente crítico como se fosse o objeto. Assim, uma perda objetal 
torna-se uma perda egoica, na qual perder o objeto de amor é perder a si mesmo. Freud (1917b/1996) destaca que a identificação é a primeira forma pela qual o ego escolhe um objeto - há nesta escolha um desejo de incorporar a si este objeto, de devorá-lo, retomando a ideia da oralidade canibalística presente na melancolia e que emerge também como tentativa de defesa no sujeito subjugado pelo complexo da mãe morta.

Tanto Freud (1917b/1996) quanto Green (1988) destacam o papel da ambivalência na psicodinâmica dos estados melancólicos. Considerando que as ocasiões que podem dar margem a esta afecção são geralmente permeadas por situações de desconsideração, desprezo ou desapontamento, elas podem trazer para a relação sentimentos opostos de amor e ódio, reforçando uma ambivalência já existente. Nestas condições,

se o amor pelo objeto - um amor que não pode ser renunciado, embora o próprio objeto o seja - se refugiar na identificação narcísica, então o ódio entra em ação nesse objeto substitutivo, dele abusando, degradando-o, fazendo-o sofrer e tirando satisfação sádica de seu sofrimento (Freud, 1917b/1996, p. 256).

A ambivalência é, portanto, pré-condição para a melancolia na medida em que é necessário que se ame o objeto perdido para que se identifique com ele, mas também odiá-lo. O que observamos no padecimento melancólico é uma impossibilidade de dirigir esta agressividade ao objeto, direcionando-a para o objeto incorporado dentro do próprio ego. No complexo da mãe morta, a criança fica impossibilitada de derivar a agressividade destrutiva para fora, devido à vulnerabilidade do objeto materno. Esta agressividade que não pode ser escoada pode vir a ser direcionada narcisicamente para o próprio ego, onde a mãe morta repousa incorporada.

Existe, então, na melancolia, algo de mortífero, um narcisismo que não se prestaria a autopreservação, mas à destruição, a um retorno a um estado anterior das coisas. Freud (1917b/1996) exemplifica esta tendência por meio do suicídio, já que para a concretização do suicídio o ego deve consentir com sua própria destruição; isto se dá justamente por esta capacidade de tratar a si mesmo como um objeto, dirigindo contra si mesmo a mesma hostilidade anteriormente relacionada a um objeto. Green (1988) diferencia um narcisismo primário positivo - vinculável às pulsões de vida - e um narcisismo primário negativo - vinculável às pulsões de morte -, sendo que este segundo se manifesta na clínica justamente na presença deste sentimento de vazio, que é sempre resultado de uma ferida narcisista com desperdício libidinal. Portanto, as obesidades que se configuram a partir de um posicionamento melancólico, com presença de queixas de sentimentos de vazio e de autoenvilecimento, relacionam-se com as expressões em ato da pulsão de morte, constituindo o ato de comer uma tentativa de escoamento pulsional imediato da angústia do vazio por intermédio de uma tentativa literal de incorporar novos objetos.

Freud (1917b/1996) destaca que uma característica notável da melancolia é sua tendência em se transformar em mania. O conteúdo é o mesmo nas duas afecções, porém, enquanto na melancolia o ego sucumbe ao 'complexo', na mania, ele é dominado e posto de lado. Há também uma explicação econômica para esta tendência, se pensarmos em um grande dispêndio de energia que se torna desnecessário e, portanto, se encontra disponível, o que torna a mania possível. Na mania, o ego deve ter superado a perda do objeto (ou seu luto pela perda), liberando uma grande cota de catexias, assim, "o indivíduo maníaco demonstra claramente sua liberação do objeto que causou seu sofrimento, procurando, como um homem vorazmente faminto, novas catexias objetais" (Freud, 1917b/1996, p. 260).

A mania seria expressa justamente na forma de uma ação que tentaria, então, superar a dor da perda do objeto, uma tentativa de se religar ao mundo, de preencher o vazio insuportável que habita o sujeito. A mania consiste, portanto, no oposto da melancolia, sendo caracterizada por intensa agitação e por um desejo voraz de estabelecer novos vínculos objetais. Assim como na melancolia, há o assujeitamento do ser, isto é, o sujeito não possui autonomia sobre o que faz e, diante disso, há um sofrimento implicado. Pensando na questão da obesidade, entendemos que a devoração voraz, no entanto, falha nesta tentativa de estabelecer catexias objetais, sendo geralmente uma atividade solitária, de isolamento, próxima do embotamento melancólico. A comida parece ficar a serviço da pulsão de morte, buscando a restauração do equilíbrio nirvânico, tentativa de aplacar toda dor, sem espaço para a representação.

Vimos em Fédida (1978) que esta pulsionalidade devoradora que busca superar a perda do objeto 
através de sua incorporação seria uma tentativa de manter o objeto vivo, referindo-se a esta superação da perda do objeto. Assim, a obesidade surgiria como consequência de uma tentativa desmedida do sujeito de se religar ao mundo, ou seja, consistiria em uma tentativa de superar a dor melancólica de ter perdido um objeto de amor. Podemos pensar que o indivíduo obeso tenta desesperadamente "engolir" o outro, guardá-lo dentro de si, preenchendo o vazio que a perda deste objeto inscreveu. Esta voracidade também traz uma característica mortífera, podendo inclusive acarretar um maior risco de morte, como observamos nos casos de obesidade mórbida, marcando uma tentativa - patológica - de superação e de proteção ante o vazio da perda do objeto.

No entanto, estas tentativas canibalísticas de incorporar novos objetos estão fadadas ao fracasso, pois, de acordo com Green (1988):

O percurso do sujeito evoca a caça em busca de um objeto inintrojetável, sem possibilidade de a ele renunciar ou perdê-lo e tampouco com possibilidade de aceitar sua introjeção no Eu investido pela mãe morta. Em suma, os objetos do sujeito ficam sempre no limite do $\mathrm{Eu}$, nem completamente dentro nem totalmente fora. $E$ isto porque o lugar está ocupado, no centro, pela mãe morta (Green, 1988, p. 252).

O sujeito obeso teria então, uma fome real de introjeção ${ }^{3}$, um desejo de alargar seu ego. No entanto, tal introjeção não pode ser realizada, pois seu ego está "cheio de vazio", identificado com o buraco deixado pela mãe morta. O obeso tentaria solucionar este problema em uma posição melancólica que propõe uma tentativa de "introjeção" imediata, mas meramente fantasística e ilusória (Abraham, \& Torok, 1987), engolindo e incorporando objetos, alargando seu invólucro corporal, mas sem enriquecer seu ego.

Nestes termos, ao pensarmos em uma "obesidade melancólica", destacamos dois aspectos referentes ao processo de identificação. O primeiro aspecto refere-se ao próprio padecimento melancólico, no qual entramos em contato com o mecanismo de identificação por meio do ódio que o sujeito sente pelo objeto perdido, mas que direciona ao próprio eu. O segundo aspecto, por sua vez, refere-se à obesidade, pois se tratando de uma regressão a uma fase oral (Freud, 1923/1996), poderíamos compreender o porquê do individuo utilizar sua oralidade como forma de defesa diante do sofrimento da perda do objeto.

A melancolia, portanto, não estaria ligada ao campo das pulsões sexuais e representáveis, mas sim à pulsão de morte, de destruição, uma pulsão irrepresentável. Neste sentido, a obesidade constituída a partir da melancolia não obedeceria ao mecanismo de formação do sintoma no sentido do evitamento do desprazer, mas sim, se submeteria ao funcionamento das neuroses narcísicas, no qual o objetivo seria evitar a angústia motivada pela perda - real ou ideal - de um objeto de amor.

\section{A cirurgia bariátrica}

Freud (1893/1996), em seus estudos sobre a histeria, observou que a simples eliminação de um sintoma sem o trabalho analítico adequado levaria o paciente à escolha (inconsciente) de um novo sintoma para diminuir a tensão do aparelho psíquico. No entanto, vimos que existe uma dimensão pulsional que não se submeteria ao crivo do recalque e do mecanismo de formação dos sintomas e que, por não ingressarem em uma rede de representações, se fazem presentes sob a forma de repetições, de atos e de manifestações corporais, estando situados "além do princípio do prazer".

As cirurgias bariátricas, especialmente as restritivas, propõem uma diminuição da capacidade estomacal, levando a um impedimento físico da ingestão alimentar e uma consequente perda de peso. Porém, ao pensarmos no comer do obeso não apenas como um comportamento alimentar, mas sim como tentativa de escoamento pulsional, somos levados a questionar as consequências da simples supressão deste ato. Cabe destacar que a relação com a comida representa, mais do que um "tipo" de alimentação, uma maneira particular de se relacionar consigo e com o mundo, uma fixação libidinal que pode trazer sofrimento.

Encontramos na literatura casos nos quais os pacientes desenvolvem transtornos alimentares ou adicções após a cirurgia bariátrica (Cordás et al, 2004). Em tais casos, a restrição física da cirurgia

\footnotetext{
${ }^{3}$ Termo introduzido por Ferenczi, refente a um mecanismo que permite incluir objetos do mundo exterior no Ego, consequência de um amor objetal e que implica no alargamento do ego (Abraham \& Torok, 1987).
} 
impede que a atuação do obeso se mantenha, impossibilitando-o de satisfazer de maneira imediata suas necessidades pulsionais, forçando-o a buscar o caminho mais rápido para a descarga da excitação para fora do aparelho psíquico.

Minerbo (2009, p. 113) define que um objeto narcísico seria "essencial para a sobrevivência do ego quando exerce a função de evitar - ou de processar-, angústias que, de outra forma, o invadiriam e o desorganizariam". Na obesidade, observamos esta relação entre o sujeito e a comida: o alimento seria, portanto, um substituto objetal que se prestaria a evitar uma angústia intensa diante da perda de um objeto primário, relacionada a um padecimento melancólico. Somos levados a questionar as consequências, então, do rompimento forçado desta ligação, imposto pela cirurgia bariátrica, que poderia levar o sujeito a buscar, de forma compulsiva, outro objeto de satisfação.

Portanto, as obesidades que se manifestam como uma tentativa de expressar por meio de um ato (o comer excessivo) uma pulsão irrepresentável, consistiriam também em uma tentativa de aplacar estados emocionais calcados em uma angústia narcísica, apresentando grande resistência a regimes e dietas alimentares. A intensidade da relação com o objeto externo representado pela comida, que não é buscada nem por uma necessidade nutricional, nem necessariamente para a obtenção de prazer, mas sim por um registro de necessidade, de sobrevivência psíquica, ao mesmo tempo, comporta uma característica melancólica, ao se colocar a serviço das pulsões agressivas, direcionadas ao próprio eu.

Fenomenologicamente, observamos que a obesidade enquanto sintoma e a obesidade como expressão de um luto inelaborável apresentam-se de maneira bastante similar. No entanto, os mecanismos subjacentes a tais fenômenos são diferentes e, por esta razão, exigem um posicionamento diferenciado por parte do terapeuta no momento da intervenção, bem como uma escuta mais criteriosa durante as avaliações pré-cirúrgicas. O papel do terapeuta não deve buscar apenas a erradicação dos comportamentos alimentares que estão causando a obesidade, mas sim buscar uma compreensão do sofrimento subjacente a este sujeito como o modo pelo qual este se relaciona com o mundo, permitindo que ele se apodere dos ensinamentos que esta percepção de seu sofrimento pode lhe trazer.
Para Minerbo (2009. p. 34), "poderíamos usar o termo 'sintoma' em um sentido amplo, e sempre de uma perspectiva metapsicológica, referindo-o às restrições, limitações e às repetições que a manutenção das defesas - qualquer defesa, neurótica ou não - impõe ao sujeito psíquico". Retomando a proposta da Psicopatologia Fundamental, este movimento colocaria o pathos do sujeito em destaque, devolvendo a dignidade de seu sofrimento e resgatando a noção de pathei matos, ou seja, aquilo que o sofrimento ensina, de resgatar o pathos e escutar o sujeito que traz sua experiência única, transformando aquilo que causa sofrimento em experiência (Ceccarelli, 2005).

Por fim, é importante que os psicólogos superem a mera observação de comportamentosalimentares-sejam eles patológicos ou não - e busquem compreender o sofrimento e os modos de funcionamento psíquico associados a essas sintomatologias. Freud (1937/1996) diz que em algumas situações o analista deve renunciar ao objetivo de recuperar a verdade histórica, propondo um tipo de interpretação que pretende construir ou reconstruir uma história esquecida, de uma época anterior a aquisição da linguagem. De acordo com Minerbo, tal trabalho de construção exige um tipo de atividade psíquica que convoca $o$ analista a estabelecer com o paciente uma comunicação pré-verbal, "onde o afeto de um entra em ressonância com o do outro, permitindo que o analista se identifique em nível profundo com seu paciente" (2012, p. 150), possibilitando, assim, criar representações, construir significados com o paciente.

É importante destacar que a prevalência de defesas orais - característica da melancolia - fortalece o registro do infantil que se desenrola na cena analítica, cabendo ao analista, muitas vezes, o papel de assumir temporariamente as funções de um objeto primário precariamente inscrito no indivíduo, suportando os ataques do paciente e possibilitando novas identificações, novas significações e, sobretudo, favorecendo a introjeção de objetos internos continentes e protetivos, possibilitando, assim, ao paciente o desenvolvimento de uma menor dependência de objetos externos, incluindo, mas não se limitando à comida. Um estudo mais aprofundado desta dinâmica de transferência poderá contribuir a disponibilizar recurso científico que possibilite auxílio ante ao sofrimento subjacente à obesidade. Daí a importância da terapia tanto antes quanto após a cirurgia. 


\section{Referências}

Abraham, N, \& Torok, M. (1987). A casca e o núcleo. São Paulo, SP: Escuta.

American Psychiatric Association. (2014). DSM-5: manual diagnóstico e estatístico de transtornos mentais. Porto Alegre, RS: Artmed.

Associação Universitária de Pesquisa em Psicopatologia Fundamental. (2016). Psicopatologia fundamental: o que é. Recuperado de http:/ /www.fundamentalpsychopathology.org/pagina-psicopatologia-fundamental-o-que-e-11

Berlinck, M. T. (2010). A noção de subjetividade na psicopatologia fundamental. Revista Latinoamericana de Psicopatologia Fundamental, 13(4),551-557. http://dx.doi.org/10.1590/S1415-47142010000400001

Berlinck, M. T. (1997). O que é psicopatologia fundamental. Psicologia: Ciência e Profissão, 17(2),13-20. http://dx.doi.org/10.1590/S1414-98931997000200003

Berlinck, M. T. (2000). Psicopatologia fundamental. São Paulo, SP: Escuta.

Ceccarelli, P. R. (2005). O sofrimento psíquico na perspectiva da psicopatologia fundamental. Psicologia em Estudo, 10(3),471-477. http://dx.doi.org/10.1590/S1413-73722005000300015

Cordás, T. A. (2004). Transtornos alimentares: classificação e diagnóstico. Revista de Psiquiatria Clínica, 31(4),154-157. http://dx.doi.org/10.1590/S0101-60832004000400003

Cordás, T. A., Lopes Filho, A. P., \& Segal, A. (2004). Transtorno alimentar e cirurgia bariátrica: relato de caso. Arquivos Brasileiros de Endocrinologiae Metabologia, 48(4), 564-571.http://dx.doi.org/10.1590/S0004-27302004000400019

Coutinho, W. (1999). Consenso latino-americano de obesidade: até onde já chegamos. Arquivos Brasileiros de Endocrinologia e Metabologia, 43(1),21-67. http://dx.doi.org/10.1590/S0004-27301999000100003

Fédida, P. (1978). L'absence. Paris: Gallimard.

Freud, S. (1996). A interpretação dos sonhos In Edição standard brasileira das obras psicológicas completas de Sigmund Freud (Vols. 4-5). Rio de Janeiro, RJ: Imago. (Trabalho original publicado em 1900).

Freud, S. (1996). Além do princípio do prazer. In Edição standard brasileira das obras psicológicas completas de Sigmund Freud (Vol. 18, pp. 13-75). Rio de Janeiro, RJ: Imago. (Trabalho original publicado em 1920).

Freud, S. (1996). Conferências introdutórias sobre psicanálise. In Edição standard brasileira das obras psicológicas completas de Sigmund Freud (Vol. 16, pp. 293-309). Rio de Janeiro, RJ: Imago. (Trabalho original publicado em 1917a).

Freud, S. (1996). Construções em análise. In Edição Standard Brasileira das Obras Psicológicas Completas de Sigmund Freud (Vol. 23, pp. 275-290). Rio de Janeiro, RJ: Imago. (Trabalho original publicado em 1937).

Freud, S. (1996). Esboço de psicanálise. In Edição standard brasileira das obras psicológicas completas de Sigmund Freud (Vol. 23, pp. 151-223). Rio de Janeiro, RJ: Imago. (Trabalho original publicado em 1938).

Freud, S. (1996). Luto e melancolia. In Edição standard brasileira das obras psicológicas completas de Sigmund Freud (Vol. 14, pp. 245-270). Rio de Janeiro, RJ: Imago. (Trabalho original publicado em 1917b).

Freud, S. (1996). O Ego e o Id. In Edição standard brasileira das obras psicológicas completas de Sigmund Freud (Vol. 19, pp. 13-77). Rio de Janeiro, RJ: Imago. (Trabalho original publicado em 1923).

Freud, S. (1996). Os instintos e suas vicissitudes. In Edição standard brasileira das obras psicológicas completas de Sigmund Freud (Vol. 14, pp. 117-146). Rio de Janeiro, RJ: Imago. (Trabalho original publicado em 1915).

Freud, S. (1996). Rascunho E. In Edição standard brasileira das obras psicológicas completas de Sigmund Freud (Vol. 1, pp. 235-241). Rio de Janeiro, RJ: Imago. (Trabalho original publicado em 1894).

Freud, S. (1996). Rascunho G. In Edição standard brasileira das obras psicológicas completas de Sigmund Freud (Vol. 1, pp. 246-253). Rio de Janeiro, RJ: Imago. (Trabalho original publicado em 1895).

Freud, S. (1996). Sobre o narcisismo: uma introdução. In Edição standard brasileira das obras psicológicas completas de Sigmund Freud (Vols 14, pp. 81-110). Rio de Janeiro. RJ: Imago. (Trabalho original publicado em 1914). 
Freud, S. (1996). Sobre o mecanismo psíquico de formação dos fenômenos histéricos: comunicação preliminar In Edição standard brasileira das obras psicológicas completas de Sigmund Freud (Vol. 2, pp. 1-57). Rio de Janeiro, RJ: Imago. (Trabalho original publicado em 1893).

Freud, S. (1996). Três ensaios sobre a teoria da sexualidade. In Edição standard brasileira das obras psicológicas completas de Sigmund Freud (Vol. 7, pp. 163-195). Rio de Janeiro, RJ: Imago. (Trabalho original publicado em 1905).

Green, A. (1988). A mãe morta. In A. Green, Narcisismo de vida, narcisismo de morte (pp. 239-275). São Paulo, SP: Escuta.

Gurfinkel, D. (2011). Adicções. São Paulo, SP: Casa do Psicólogo.

Laplanche, J., \& Pontalis, J. B. (2001). Vocabulário de psicanálise. São Paulo, SP: Martins Fontes.

Loli, M. S. A. (2000). Obesidade como sintoma: uma leitura psicanalítica. São Paulo, SP:Vetor.

Melo, M. E. (2011). Os números da obesidade no Brasil: Vigitel 2009 e POF 2008-2009. Recuperado de http://www. abeso.org.br/pdf/Obesidade\%20no\%20Brasil\%20VIGITEL\%202009\%20POF2008_09\%20\%20II.pdf

Minerbo, M. (2009). Neurose e não-neurose. São Paulo, SP: Casa do Psicólogo.

Minerbo, M. (2012). Transferência e contratransferência. São Paulo, SP. Casa do Psicólogo.

Oliveira, V. M., Linardi, R. C., \& Azevedo, A. P. (2004). Cirurgia bariátrica: aspectos psicológicos e psiquiátricos. Revista de Psiquiatria Clínica, 31(4), 199-201. http://dx.doi.org/10.1590/S0101-60832004000400014

Organização Mundial de Saúde. (1993). Classificação de transtornos mentais e de comportamento da CID-10: descrições clínicas e diretrizes diagnósticas. Porto Alegre, RS: Artes Médicas.

Pinheiro, M.T. S., Quintella, R. R., \&Verztmann, J. S. (2010). Distinção teórico-clínica entre depressão, luto e melancolia. Revista de Psiquiatria Clínica, 22(2), 147-168. http://dx.doi.org/10.1590/S0103-56652010000200010

Roudinesco, E., Plon, M. (1997). Dicionário de psicanálise. Rio de Janeiro, RJ: Zahar.

Stefano, S. C., Borges, M. B. F., \& Claudino, A. M. (2002). Transtorno da compulsão alimentar periódica. Psiquiatria na Prática Médica, 24(suppl 3), 18-23.

Waters, G. S., Pories, W. J., Swanson, M. S., Meelheim, H. D., Flickinger, E. G., \& May, H. J. (1991). Long-term studies of mental health after Greenville gastric bypass operation for morbid obesity. American Journal of Surgery, 161(1), 154-158. http://dx.doi.org/10.1016/0002-9610(91)90377-P

\section{Maria Virginia Filomena Cremasco}

Universidade Federal do Paraná, PR, Brasil.

Doutorado em Ciências Médicas pela Universidade Estadual de Campinas (Unicamp, 2002). Psicanalista, Professora Associada do Departamento e do Mestrado em Psicologia da Universidade Federal do Paraná, Curitiba - PR, Brasil. E-mail: mavicremasco@gmail.com

\section{Camila Chudek Ribeiro}

Psicóloga, Mestre em Psicologia Clínica pela Universidade Federal do Paraná Universidade Federal do Paraná, Curitiba - PR, Brasil.

E-mail: camila.chudek@gmail.com

Endereço para envio de correspondência:

Praça Santos Andrade, 50 - $2^{\circ}$ andar - Centro. CEP: 80020-240

Curitiba, PR, Brasil

Recebido 13/01/2015

Reformulação 16/05/2016

Aprovado 14/03/2017 
Received $01 / 13 / 2015$

Reformulated $05 / 16 / 2016$

Approved 03/14/2017

Recebido 13/01/2015

Reformulado 16/05/2016

Aceptado 14/03/2017

Como citar: Cremasco, M. V. F., \& Ribeiro, C. C. (2017). Quando a cirurgia falha: implicações da melancolia na cirurgia da obesidade. Psicologia: Ciência e Profissão, 37(2), 258-272. https://doi.org/10.1590/1982-370300132015

How to cite: Cremasco, M. V. F., \& Ribeiro, C. C. (2017). When surgery fails: the implications of melancholia in the surgical treatment of obesity. Psicologia: Ciência e Profissão, 37(1), 258-272.

https://doi.org/10.1590/1982-370300132015

Cómo citar: Cremasco, M. V. F., \& Ribeiro, C. C. (2017). Cuando la cirugía falla: implicaciones de la melancolía para el tratamiento quirúrgico de la obesidad. Psicologia: Ciência e Profissão, 37(1), 258-272. https://doi.org/10.1590/1982-370300132015 